\title{
C-type natriuretic peptide stimulates osteoblastic proliferation and collagen- $X$ expression but suppresses fibroblast growth factor-23 expression in vitro
}

Wei Xia Chen ${ }^{\dagger}$, Hui Hui Liư ${ }^{\dagger}$, Rui Xue Li, Goshgar Mammadov, Jing Jing Wang, Fei Fei Liu, Sama Samadli, Yang Fang Wu, Dong Dong Zhang, Huang Huang Luo and Peng Hu* (D)

\begin{abstract}
Background: The effects of C-type natriuretic peptide (CNP) and fibroblast growth factor (FGF)-23 appear to oppose each other during the process of bone formation, whereas few studies exist on the interaction between CNP and FGF-23. The main objective of the present study is to probe whether CNP is directly responsible for the regulation of osteoblast or via antagonizing FGF-23.

Methods: Osteoblasts were cultured in the absence or presence of $\operatorname{CNP}(0,10$, and $100 \mathrm{pmol} / \mathrm{L})$ for $24 \mathrm{~h}, 48 \mathrm{~h}$ and $72 \mathrm{~h}$, respectively.

Results: The findings of the present study indicated that: (1) CNP significantly stimulated osteoblastic proliferation and collagen (Col)-X expression; (2) both osteoblastic (osteocalcin, procollagen type I carboxy-terminal propeptide, total alkaline phosphatase and bone-specific alkaline phosphatase) and osteolytic (tartrate-resistant acid phosphatase and cross-linked carboxyterminal telopeptide of type I collagen) bone turnover biomarkers were upregulated by CNP in osteoblasts; (3) FGF-23 mRNA and protein were significantly down-regulated at $24 \mathrm{~h}$ by CNP in osteoblasts, but the expression of FGF receptor-1/Klotho had no significant change.

Conclusions: CNP stimulates osteoblastic proliferation and Col-X expression via the down-regulation of FGF-23 possibly in vitro. However, the specific mechanisms of the interaction between CNP and FGF-23 in osteoblasts are still unclear according to our findings. A further study on osteoblasts cultured with CNP and FGF-23 inhibitor will be undertaken in our laboratory.
\end{abstract}

Keywords: Bone formation, C-type natriuretic peptide, Fibroblast growth factor-23, Osteoblast, Klotho

\footnotetext{
* Correspondence: hupeng28@aliyun.com

tWei Xia Chen and Hui Hui Liu are contributed equally to this work and should be considered co-first authors.

Department of Pediatrics, The First Affiliated Hospital of Anhui Medical

University, No. 218 Ji-Xi Road, Hefei, Anhui Province 230032, PR China
}

C C The Author(s). 2020 Open Access This article is licensed under a Creative Commons Attribution 4.0 International License, which permits use, sharing, adaptation, distribution and reproduction in any medium or format, as long as you give appropriate credit to the original author(s) and the source, provide a link to the Creative Commons licence, and indicate if changes were made. The images or other third party material in this article are included in the article's Creative Commons licence, unless indicated otherwise in a credit line to the material. If material is not included in the article's Creative Commons licence and your intended use is not permitted by statutory regulation or exceeds the permitted use, you will need to obtain permission directly from the copyright holder. To view a copy of this licence, visit http://creativecommons.org/licenses/by/4.0/ The Creative Commons Public Domain Dedication waiver (http://creativecommons.org/publicdomain/zero/1.0/) applies to the data made available in this article, unless otherwise stated in a credit line to the data. 


\section{Introduction}

C-type natriuretic peptide (CNP) is an endotheliumderived vasodilator and contains two major endogenous forms, designated CNP-53 and CNP-22 [1]. The clearance of CNP-22 in human plasma is very rapid, with a calculated half-life of $2.6 \mathrm{~min}$, shorter than that of CNP$53[2,3]$. Both of them could result in a significant elevation in intracellular cyclic guanosine monophosphate (cGMP) after selectively binding to the transmembrane natriuretic peptide receptor (NPR)-B [4, 5]. Besides little effect on blood pressure and body fluid homeostasis, CNP mainly elicits local vasorelaxation, inhibits organ remodeling, accelerates reendothelialization, and antagonizes the renin-angiotensin-aldosterone system in a paracrine manner [6-8]. However, several lines of evidence have disclosed that CNP also plays a pivotal role in longitudinal bone growth. Tassano et al. [9] identified the partially overlapping chromosome $2 \mathrm{q} 37$ deletions in two patients characterized by short stature and skeletal overgrowth, respectively; the former resulted from the loss of one copy of the CNP precursor gene (NPPC) with normal plasma CNP, whereas the latter was affected by overexpression of the NPPC and elevation of plasma CNP. Moreover, the heterozygous mutations within the ring structure of CNP could also lead to NPR-B inactivation, cGMP down-regulation and eventually a phenotype of short stature and small hands [10], which is consistent with the previous findings of functional mutation researches on $N P R-B$ gene $[11,12]$. In $N p p c^{-/-}$mice, the impaired endochondral ossification contributed to early death and severe dwarfism was prevalent in survivals; in contrast, the targeted transgenesis of CNP in the growth plate chondrocytes could rescue the skeletal defect of $\mathrm{Nppc}^{-1-}$ mice [13]. In addition, a dramatic impairment of endochondral ossification and an attenuation of longitudinal vertebra or limb-bone growth were also found in $N p r-b^{-1-}$ mice, whereas the above skeletal abnormalities could be recovered by Npr-b overexpression [14]. Therefore, CNP signaling serves as a physiological stimulator of bone growth.

Over the past decades, a few studies in vitro were devoted to the effect of CNP on osteoblasts with a certain controversy. Hagiwara et al. [15] cultured rat osteoblasts with CNP $\left(10^{-7} \mathrm{M}\right)$ for 15 days and found that alkaline phosphate (ALP) / osteocalcin transcript and the mineralization of nodules were significantly stimulated with a dose-dependent reduction in the rate of DNA synthesis. However, another study revealed that the constant high ALP activity in mouse osteoblasts was not significantly affected by exogenous CNP $\left(10^{-9}-10^{-5} \mathrm{M}\right)$ after a 48-h treatment [16]. Therefore, it should be further elucidated whether the regulatory effect of CNP is a direct consequence on osteoblastic differentiation or mediated by the other cytokines.
Fibroblast growth factor (FGF)-23 is an osteoblastderived endocrine regulator of phosphate homeostasis through binding to FGF receptor (FGFR)-1 and the coreceptor Klotho, and mainly involved in bone formation $[17,18]$. Shimada et al. [19] established an FGF-23 null mouse model and observed that $F g f-23^{-1-}$ mice showed significant hyperphosphatemia, severe growth retardation and short life-span. On the contrary, Larsson et al. [20] generated transgenic mice overexpressing human FGF-23 and found that FGF-23 transgenic mice recapitulated the biochemical and skeletal abnormalities similar to human autosomal dominant hypophosphatemic rickets, oncogenic osteomalacia and X-linked hypophosphatemia. Consistently, Wang et al. [21] transfected human FGF-23 into osteoblasts in vitro and found that overexpressed FGF-23 could significantly suppress osteoblastic differentiation and matrix mineralization. In this context, the main objective of the present study is to probe whether CNP is directly responsible for the regulation of osteoblast or via antagonizing FGF-23 in vitro.

\section{Materials and methods Cell culture}

The isolation and culture of osteoblasts were based on the previous study by Declercq et al. [22]. Primary rat calvariae cells (osteoblast-like cells) were isolated from 24h-old male Sprague Dawley rats, in accordance with the permission of our medical ethics committee (No. LLSC20150009). Briefly, calvariae was dissected and sectioned into fractions. After digestion with $0.1 \%$ type II collagenase for $1 \mathrm{~h}$, cells were incubated in $\alpha$-modified Eagle's medium ( $\alpha$-MEM; 0.25\%; MDL biotech, Beijing, China) supplemented with $12 \%$ fetal bovine serum and $1 \%$ penicillin/streptomycin at $37{ }^{\circ} \mathrm{C}$ in a humidified atmosphere of $95 \%$ air and $5 \% \mathrm{CO}_{2}$. The medium was changed every day and cells from passage 2 to 5 were used in this study. Subsequently, cells were seeded onto 96-well plates at a density of $5.0 \times 10^{3} / \mathrm{cm}^{2}$ and cultured in $\alpha$-MEM supplemented with ascorbic acid, $\beta$ glycerophosphate and dexamethasone $(50 \mu \mathrm{mol} / \mathrm{L}, 10$ $\mathrm{mmol} / \mathrm{L}$ and $100 \mathrm{nmol} / \mathrm{L}$, respectively; MDL biotech, Beijing, China) in the absence or presence of CNP-53 (0, 10, and $100 \mathrm{pmol} / \mathrm{L}$; Sangon Biotech, Shanghai, China) for $24 \mathrm{~h}, 48 \mathrm{~h}$ and $72 \mathrm{~h}$, respectively, for its longer halflife than CNP-22.

\section{Cell proliferation assays}

The cell proliferation was measured using the 3-[4,5dimethylthiazolyl]-2,5-diphenyltetrazolium bromide assay (MTT assay). Briefly, cells were seeded in 96-well plates and cultured in the absence or presence of CNP-53 $(0,10$, and $100 \mathrm{pmlo} / \mathrm{L}$ ) for $24 \mathrm{~h}, 48 \mathrm{~h}$ and $72 \mathrm{~h}$, respectively. Therefore, the cells were then incubated with MTT (MDL biotech, Beijing, China) for another $4 \mathrm{~h}$. Subsequently, the 
supernatants were removed and the formazan crystals were solubilized in DMSO (MDL biotech, Beijing, China) by constant shaking for $10 \mathrm{~min}$. Finally, optical density (OD) was quantified at $490 \mathrm{~nm}$ wavelength using an absorbance reader (ELx800; Biotek Inc., Winooski, VT, USA).

\section{Enzyme-linked immunosorbent assay (ELISA)}

The protein levels of bone biomarkers and FGF-23 in the cultured supernatants were determined using commercially available ELISA kits (MDL biotech, Beijing, China) according to the manufacturer's protocols, including rat osteocalcin (OC) ELISA kit (SEA471Ra), rat procollagen type I carboxy-terminal propeptide (PICP) ELISA kit (SEA570Ra), rat total alkaline phosphatase (tAP) ELISA kit (MD7205), rat bone-specific alkaline phosphatase (bAP) ELISA kit (MD7101), rat tartrate-resistant acid phosphatase (TRAP) ELISA kit (MD7077), cross-linked carboxyterminal telopeptide of type I collagen (ICTP) ELISA kit (MD7064) and rat FGF-23 ELISA kit (MD7106).

\section{Real-time PCR}

Real-time PCR was undertaken with the ABI 7900 sequence detection system (Applied Biosystems, Foster City, CA) using SYBR Green PCR Master Mix (Applied Biosystems, Foster City, CA) in accordance with the manufacturer's instructions. Total RNA was extracted from cultured osteoblasts by Trizol (ABI-Invitrogen) extraction. Ultraviolet spectrophotometer measuring absorbance and agarose gel electrophoresis confirmed that there had been no degradation of RNA. Among this, $200 \mathrm{ng}$ of isolated RNA were reverse transcribed into cDNA using a SuperScript III RT reagent kit (ABI-Invitrogen). Specific oligonucleotide primers used in the present study were as follows: for FGF-23, sense: 5 '-TGG CCA TGT AGA CGG AAC AC-3', antisense: 5'-GTA GCC GTT CTC TAG CGT CC-3'; for FGFR-1, sense: 5' CTG GAC CTG AGG CAT CAG TAG-3', antisense: 5' AAG CAG CAG CAA TTT TTA TTG AG-3'; for Klotho, sense: $5^{\prime}$-GAC GGG GTT GTA GCC AAG AA-3', antisense: 5'-CCC AGT CTA GGG AGA ACC GA-3'; for collagen (Col)-X, sense: $5^{\prime}$-TCC CAG GAT TCC CTG GAT CTA A-3', antisense: 5'-AGG TAT GAC TGC TTG GCT GG-3'; for glyceraldehyde-3-phosphate dehydrogenase (GAPDH), sense: $5^{\prime}$-GTT ACC AGG GCT GCC TTC TC-3', antisense: 5'-GGG TTT CCC GTT GAT GAC C-3'. Amplification conditions included predenaturing at $95^{\circ} \mathrm{C}$ for $2 \mathrm{~min}$; then denaturation at $94^{\circ} \mathrm{C}$ for $20 \mathrm{~s}$, annealing at $65^{\circ} \mathrm{C}$ for $20 \mathrm{~s}$, extension at $72^{\circ} \mathrm{C}$ for $30 \mathrm{~s}$; and finally experiencing forty cycles of $30 \mathrm{~s}$ at $72^{\circ} \mathrm{C}$. Gene expression was normalized using GAPDH as an endogenous control to correct for differences in the amount of total RNA originally added to each reaction. The average threshold cycle $(\mathrm{Ct}$, the cycles of template amplification to the threshold) was calculated as the value of each sample. Relative quantitative $2^{-\Delta \Delta \mathrm{Ct}}$ was used to compare the mRNA expression.

\section{Immunofluorescence staining}

Cells were incubated in 96-well plates and washed three times with cold phosphate buffer saline (PBS) and fixed with $4 \%$ paraformaldehyde for $15 \mathrm{~min}$. Subsequently, cells were washed 3 times with PBS and incubated with $0.2 \%$ Triton X-100 (Beyotime, Shanghai, China) for 20 min. After washing 3 times in PBS, cells were incubated with $1 \%$ bovine serum albumin for $30 \mathrm{~min}$ at room temperature. Cells were then incubated overnight at $4{ }^{\circ} \mathrm{C}$ with the following antibodies: anti-FGF-23, FGFR-1, Klotho and Col-X (1:50, MDL biotech, Beijing, China). Following this, cells were washed 3 times with PBS and were incubated with secondary antibodies (Donkey-antirabbit, Abcam Inc.; Donkey-anti-mouse, Abcam Inc) for $1 \mathrm{~h}$ at $37^{\circ} \mathrm{C}$ and the nucleus was labeled with 4,6 -diamidino-2-phenylindole (DAPI; $0.1 \mu \mathrm{g} / \mathrm{ml}$ ). Finally, the cells were washed with PBS and observed under a Laser scanning confocal microscopy (Nikon A1R, Tokyo, Japan). Representative images were analyzed with Image-Pro Plus 6.0 software, and the mean intensity was calculated.

\section{Western blot analysis}

Cells were cultured in 96-well plates and lysed in cold RIPA buffer (MDL biotech, Beijing, China) with protease inhibitors. Proteins were separated by sodium dodecyl sulfate-polyacrylamide gel electrophoresis and transferred onto polyvinylidene fluoride membranes (Millipore, USA). Membranes were blocked for $1 \mathrm{~h}$ at room temperature using $5 \%$ fetal bovine serum in tris-buffered saline tween (TBST). Following incubation, membranes were probed with FGF-23, FGFR-1, Klotho, Col-X and actin primary antibodies (MDL biotech, Beijing, China) at $4{ }^{\circ} \mathrm{C}$ overnight. After washing 3 times with TBST, membranes were incubated with secondary antibodies for $1 \mathrm{~h}$ at room temperature. Finally, membranes were washed 3 times with TBST, and data were captured with a chemiluminescence detection system (Bio-rad, USA).

\section{Statistical analyses}

Statistical analyses were performed using the statistical package for social studies SPSS version 23.0 (SPSS Inc., Chicago, IL). All data were obtained from at least three independent experiments and their values were presented as the mean $\pm \mathrm{SD}$. The interaction between treatment and time on bone turnover biomarkers (OC, PICP, tAP, bAP, ICTP and TRAP) were determined using two-way ANOVA. Comparison of mean values among groups was performed using one-way ANOVA, and post hoc analysis was calculated using the Student-Newman-Keuls test. $P<$ 0.05 was considered to indicate significance. 


\section{Results}

\section{CNP promoted the proliferation of osteoblasts}

Under microscope, active osteoblasts were plump, cuboidal, mononuclear cells lying on the matrix which they synthesized (Fig. 1a). The evaluation of osteoblastic proliferation is presented in Fig. 1b. Based on the result of MTT assays, CNP significantly promoted the proliferation of osteoblasts in a dose-dependent manner. More specifically, the baseline data of OD were $0.47 \pm 0.024$, $0.58 \pm 0.029$, and $0.69 \pm 0.035$ at $24 \mathrm{~h}, 48 \mathrm{~h}$, and $72 \mathrm{~h}$ in cultured cells without CNP treatment respectively. The OD value were $0.69 \pm 0.034,0.77 \pm 0.039$, and $0.77 \pm 0.038$ in the low-dose group at $24 \mathrm{~h}, 48 \mathrm{~h}$ and $72 \mathrm{~h}$ post-treatment respectively, and $0.89 \pm 0.044$, $0.89 \pm 0.044$, and $0.90 \pm 0.045$ in the high-dose group at $24 \mathrm{~h}, 48 \mathrm{~h}$ and $72 \mathrm{~h}$ post-treatment respectively. Furthermore, the high-dose group showed a 0.28-, 0.15 - and 0.17 -fold increase compared with the corresponding low-dose group at $24 \mathrm{~h}, 48 \mathrm{~h}$ and $72 \mathrm{~h}$ posttreatment respectively $(P<0.05)$.

\section{The effects of CNP on bone turnover biomarkers}

Figure 2 illustrates the supernatant levels of osteoblastic (OC, PICP, tAP, bAP) and osteolytic (TRAP and ICTP) biomarkers by ELISA. Compared with the corresponding controls, supernatant OC displayed a marked increment in both the low-dose group and high-dose group at $48 \mathrm{~h}$ and $72 \mathrm{~h}$ post-treatment, respectively (a 0.40 - and 0.70 fold increase at $48 \mathrm{~h}$; a 0.61 - and 1.01 -fold increase at $72 \mathrm{~h}$, $P<0.05)$; furthermore, supernatant $\mathrm{OC}$ experienced a 0.22 - and 0.25 -fold increase in the high-dose group at $48 \mathrm{~h}$ and $72 \mathrm{~h}$ post-treatment, compared with their lose-dose counterparts, respectively (Fig. $2 \mathrm{a}, P<0.05$ ). In comparison with the control group, supernatant PICP showed a significant elevation in both the low-dose group (a 0.61 fold increase) and high-dose group (a 1.00-fold increase) only at $72 \mathrm{~h}$ post-treatment, respectively (Fig. $2 \mathrm{~b}, P<0.05$ ). In comparison with the corresponding controls, significant higher levels of tAP and bAP were noted in the CNPtreated groups at each time point. Supernatant tAP showed a 0.32-, 0.40- and 0.61-fold increase in the lowdose group at $24 \mathrm{~h}, 48 \mathrm{~h}$ and $72 \mathrm{~h}$ post-treatment respectively, and a 0.43-, 0.70- and 1.00-fold increase in the highdose group at $24 \mathrm{~h}, 48 \mathrm{~h}$ and $72 \mathrm{~h}$ post-treatment respectively (Fig. 2c, $P<0.05$ ). Supernatant bAP showed 0.21-, 0.40 - and 0.59 -fold increase in the low-dose group at $24 \mathrm{~h}$, $48 \mathrm{~h}$ and $72 \mathrm{~h}$ post-treatment respectively, and a 0.31 -, 0.70 - and 0.99 -fold increase in the high-dose group at 24 $\mathrm{h}, 48 \mathrm{~h}$ and $72 \mathrm{~h}$ post-treatment respectively (Fig. $2 \mathrm{~d}, \mathrm{P}<$ 0.05). In addition, compared with the corresponding lowdose group, supernatant tAP presented an apparent increase in the high-dose group at $48 \mathrm{~h}$ (a 0.21 -fold increase) and $72 \mathrm{~h}$ (a 0.25 -fold increase) post-treatment (Fig. 2c, $P<$ $0.05)$, whereas the significant elevation of bAP was observed in the high-dose group only at $72 \mathrm{~h}$ post-treatment (a 0.25 -fold increase, Fig. $2 \mathrm{~d}, P<0.05$ ). In addition, compared with the corresponding low-dose group, supernatant tAP presented an apparent increase in the highdose group at $48 \mathrm{~h}$ (a 0.21 -fold increase) and $72 \mathrm{~h}$ (a 0.25 fold increase) post-treatment (Fig. $2 \mathrm{c}, P<0.05$ ), whereas the significant elevation of bAP was observed in the high-dose group only at $72 \mathrm{~h}$ post-treatment (a 0.25 fold increase, Fig. $2 \mathrm{~d}, P<0.05)$. In comparison with the corresponding controls, supernatant TRAP experienced an obvious increase in the CNP-treated groups at each time point (a 0.30-, 0.71- and 1.01-fold increase in the low-dose group at $24 \mathrm{~h}, 48 \mathrm{~h}$ and $72 \mathrm{~h}$ respectively; a 0.35 -, 0.77 - and 1.09-fold increase in the high-dose group at $24 \mathrm{~h}, 48 \mathrm{~h}$ and $72 \mathrm{~h}$, respectively, Fig. $2 \mathrm{e}, \mathrm{P}<0.05)$. Compared with the corresponding controls, supernatant ICTP were also significantly upregulated in the CNP-treated groups at $48 \mathrm{~h}$ and $72 \mathrm{~h}$ (a 0.40 - and 0.60 -fold increase in

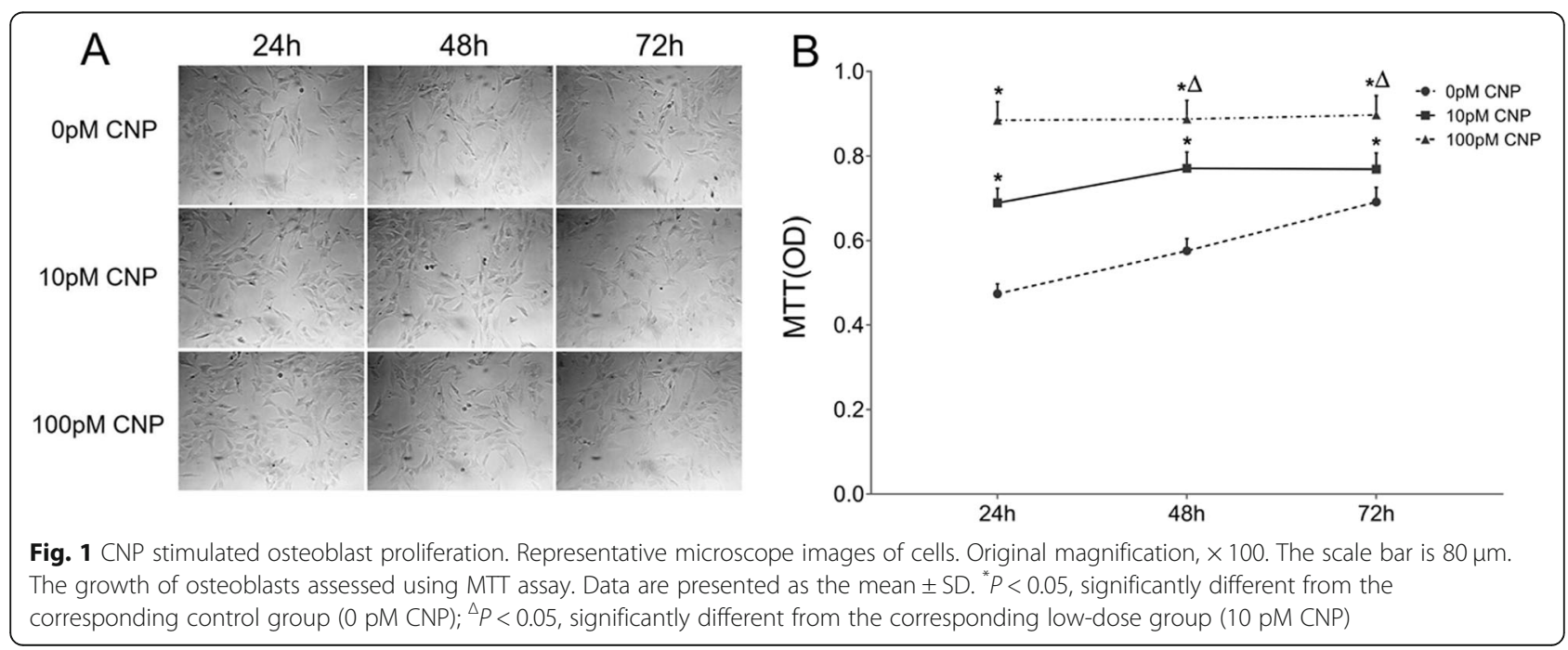



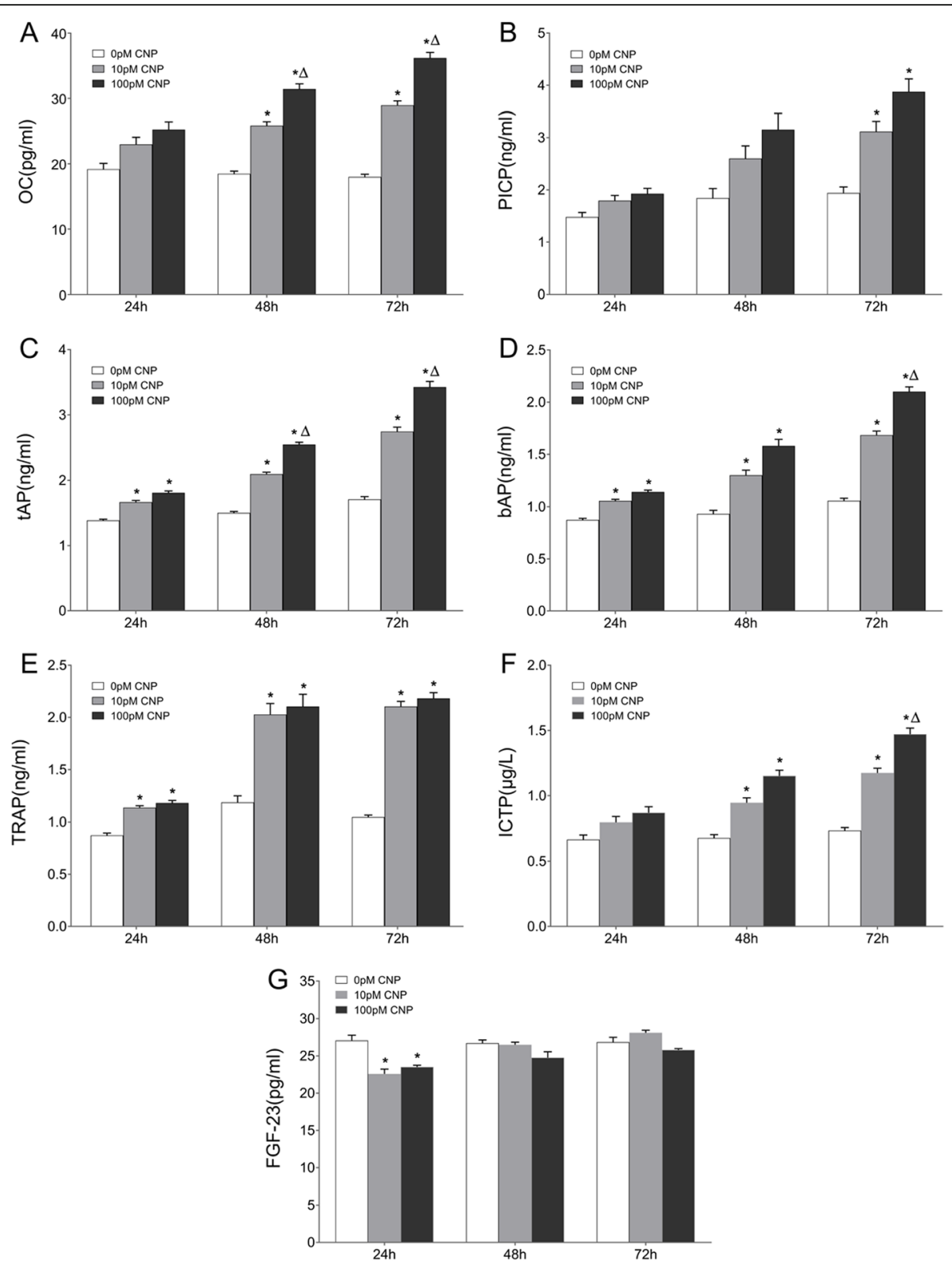

Fig. 2 ELISA analysis of OC, PICP, tAP, bAP, TRAP and ICTP in the cultured osteoblasts. The supernatant levels of (a) OC, (b) PICP, (c) tAP, (d) bAP, (e) TRAP and (f) ICTP were determined using commercially available ELISA kits after CNP treatment (96-well plates). Data are presented as the mean \pm SD. ${ }^{*} P<0.05$, significantly different from the corresponding control group $(0 \mathrm{pM} C N P)$; ${ }^{\Delta} P<0.05$, significantly different from the corresponding low-dose group (10 pM CNP)

the low-dose group at $48 \mathrm{~h}$ and $72 \mathrm{~h}$, respectively; a 0.70 - and 1.00 -fold increase in the high-dose group at $48 \mathrm{~h}$ and $72 \mathrm{~h}$, respectively, Fig. $2 \mathrm{f}, \quad P<0.05)$; in addition, supernatant ICTP exhibited a 0.25 -fold increase in the high-dose group at $72 \mathrm{~h}$ post-treatment in comparison with the corresponding low-dose counterpart (Fig. 2f, $P<0.05$ ). Subsequently, two-way ANOVA analysis revealed that CNP treatment and time had significant effects on all the bone turnover biomarkers $(F \geq 5.91, P<0.05)$.

\section{CNP upregulated col-X}

Real-time PCR analysis of Col-X mRNA is shown in Fig. 3. Compared with the corresponding control group, Col-X mRNA expression exhibited a 0.31-, 0.53- and 0.40 -fold increase in the low-dose group at $24 \mathrm{~h}, 48 \mathrm{~h}$ and $72 \mathrm{~h}$ post-treatment respectively, and a 0.50-, 0.76and 0.61 -fold increase in the high-dose group at $24 \mathrm{~h}$, $48 \mathrm{~h}$ and $72 \mathrm{~h}$ post-treatment, respectively (Fig. $3 \mathrm{a}, P<$ $0.05)$. Subsequently, the expression characterization of Col-X was confirmed using Western blot (data not 

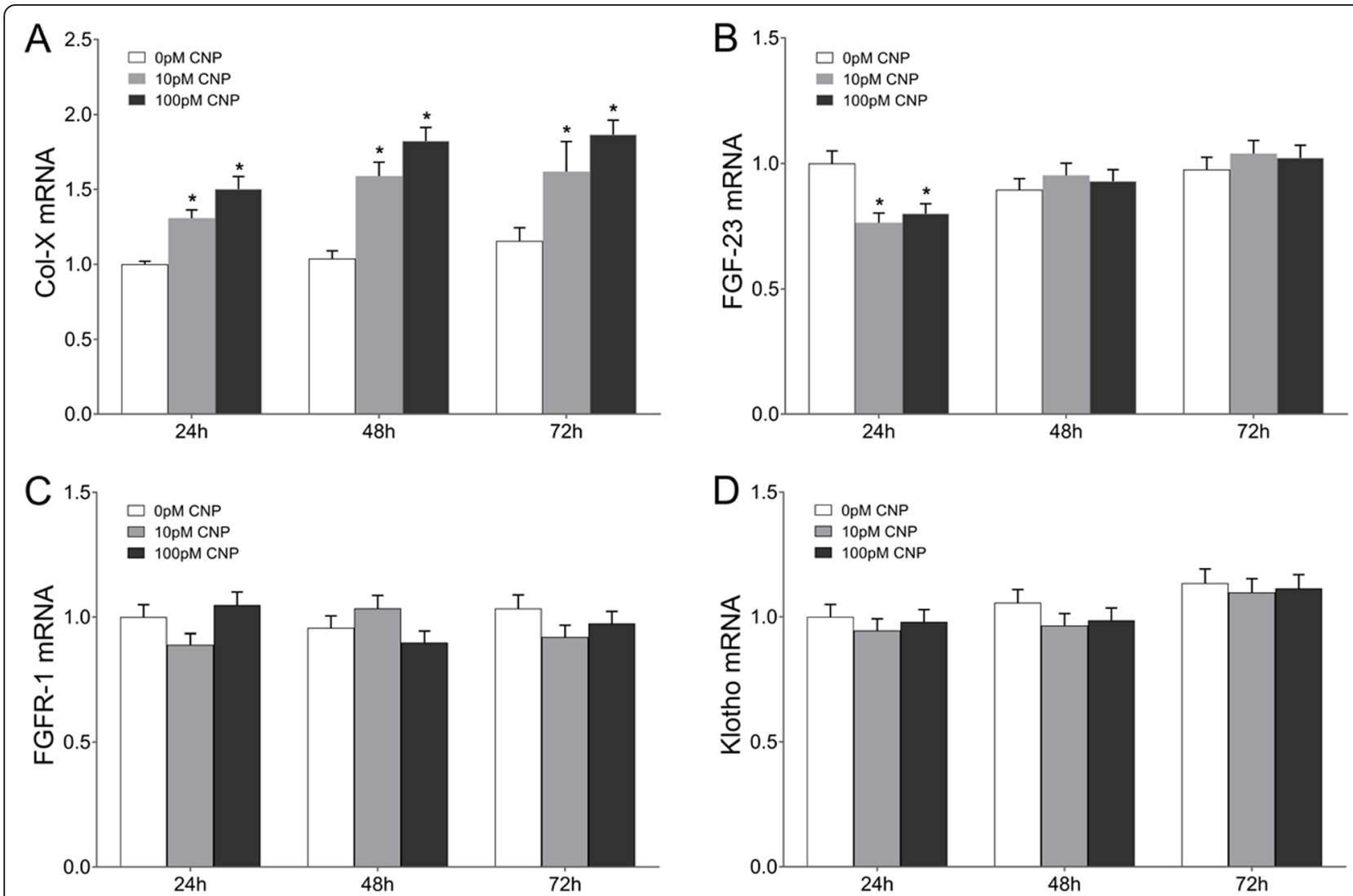

Fig. 3 Real-time PCR analysis of Col-X, FGF-23, FGFR-1, and Klotho mRNA in osteoblasts. a Col-X, b FGF-23, c FGFR-1, and d Klotho mRNA expression in osteoblasts were measured by real-time PCR (96-well plates). Data are presented as the mean \pm SD. ${ }^{*} P<0.05$, significantly different from the corresponding control group (0 pM CNP); ${ }^{\Delta} P<0.05$, significantly different from the corresponding low-dose group (10 pM CNP)

shown). Compared with the corresponding control group, the protein expression of Col-X experienced a 0.27 -, 0.24- and 0.30-fold increase in the low-dose group at $24 \mathrm{~h}, 48 \mathrm{~h}$ and $72 \mathrm{~h}$ post-treatment respectively, and a 0.39-, 0.39- and 0.64-fold increase in the high-dose group at $24 \mathrm{~h}, 48 \mathrm{~h}$ and $72 \mathrm{~h}$ post-treatment respectively $(P<0.05)$. In addition, the high-dose group showed a 0.26 -fold increase of Col-X protein than that in the lowdose group at $72 \mathrm{~h}$ post-treatment $(P<0.05)$. To clarify the distributions of Col-X protein in osteoblasts, immunofluorescence staining was performed. As shown in Fig. 4a, Col-X positive reaction was noted in both the control and CNP-treated group throughout the whole observational period, but more significant in the CNPtreated group than controls. More specifically, semiquantitative analysis indicated that the cumulative optical density per unit area (IOD/area) was significantly increased in the high-dose group at each time point, and in the low-dose group at $24 \mathrm{~h}$ and $72 \mathrm{~h}$ post-treatment, compared with the corresponding controls. Moreover, the IOD/area was greater in the high-dose group than that in the low-dose group only at $72 \mathrm{~h}$ post-treatment (Fig. 4b, $P<0.05$ ).

\section{CNP inhibited the expression of FGF-23 in the earlier phase}

Figure $2 \mathrm{~g}$ depicts the supernatant levels of FGF-23 by ELISA. Supernatant FGF-23 experienced an 18\% decrease in the low-dose group and a $13 \%$ decrease in the high-dose group only at $24 \mathrm{~h}$ post-treatment, compared with the baseline of controls $(P<0.05)$. In osteoblasts, the relative quantity of FGF-23 transcript exhibited a $24 \%$ decrease in the low-dose group and a $20 \%$ decrease in the high-dose group only at $24 \mathrm{~h}$ post-treatment (Fig. $3 b, P<0.05$ ), which was confirmed using Western blot (data not shown). In addition, immunofluorescence staining showed that the osteoblasts were positive for FGF-23 throughout the observational period, whereas its IOD/area also presented a marked decrease at $24 \mathrm{~h}$ after CNP treatment (Fig. 4c, d, $P<$ 0.05). Therefore, CNP inhibited the expression of osteoblastic FGF-23 in the earlier phase.

\section{No effect of CNP on FGFR-1/Klotho}

By real-time PCR analysis, no significant differences in FGFR-1/Klotho expression were found between the control group and the CNP-treated group at each time point 

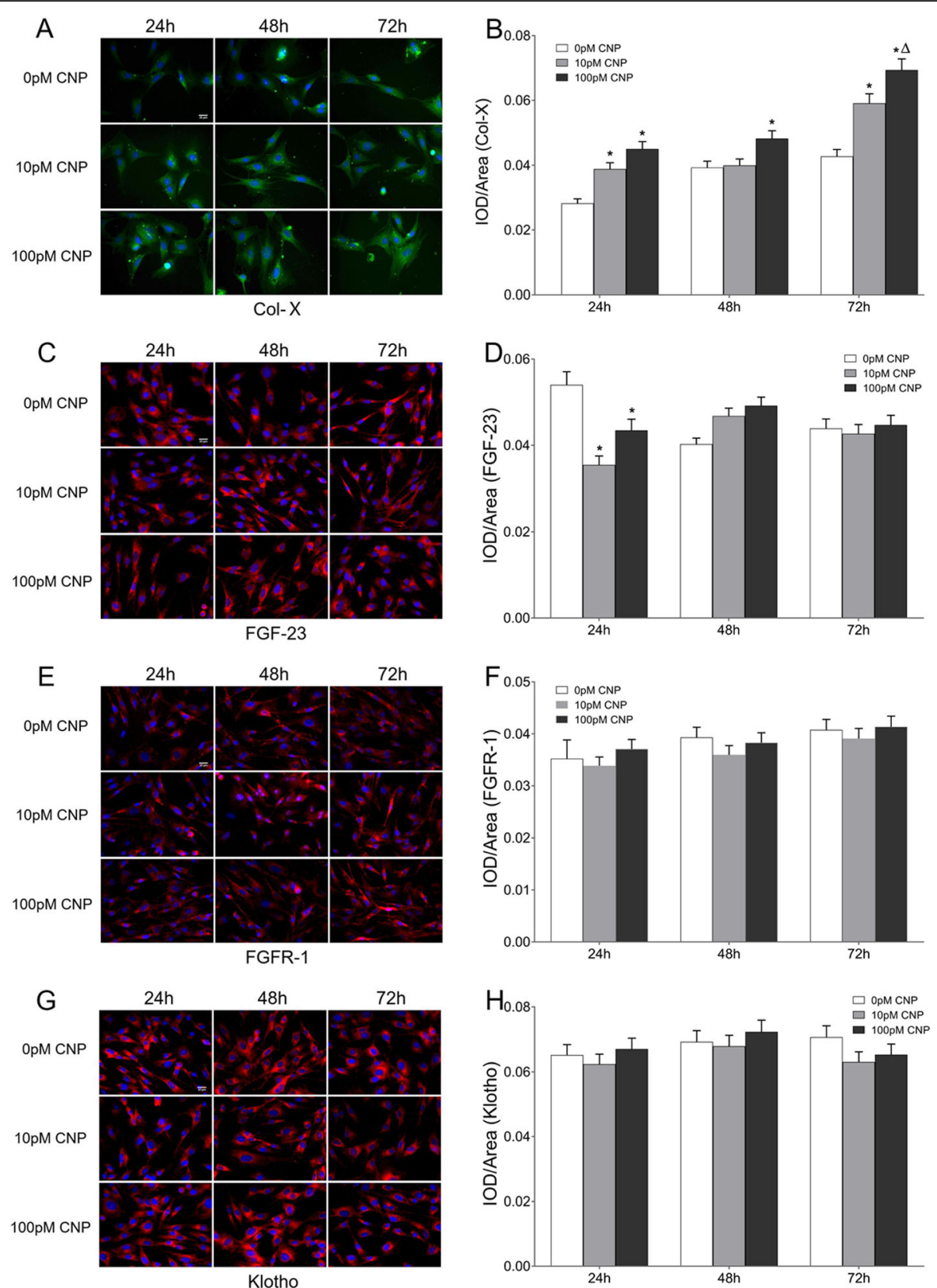

Fig. 4 Immunofluorescence staining of Col-X, FGF-23, FGFR-1 and Klotho protein in osteoblasts. Representative microscope images of cells on the coverslips with DAPI-stained nuclei (blue) and Col-X staining (green)/FGF-23 staining (red)/FGFR-1staining (red)/Klotho staining (red). Original magnification, $\times 400$. The scale bar is $20 \mu \mathrm{m}$. a Col-X, c FGF-23, e FGFR-1 and $\mathbf{g}$ Klotho. Fluorescence intensities of Col-X, FGF-23, FGFR-1 and Klotho. $\mathbf{b}$ Col-X, d FGF-23, f FGFR-1 and $\mathbf{h}$ Klotho. Data are presented as the mean \pm SD. ${ }^{*} P<0.05$, significantly different from the corresponding control group (0 pM CNP); ${ }^{\Delta} P<0.05$, significantly different from the corresponding low-dose group (10 pM CNP)

(Fig. 3, $P>0.05$ ), which was confirmed using Western blot (data not shown). FGFR-1/Klotho expression also showed a dose-independent manner after CNP treatment (Fig. 3c, d, $P<0.05$ ). In addition, immunofluorescence staining showed that osteoblasts were positive for FGFR-1/ Klotho staining in both the control and CNP-treated group throughout the whole observational period (Fig. 4e, Fig. 4g). Evaluation of IOD/area revealed no significant differences between the control group and the CNP-treated group at each time point, and the IOD/area was not in parallel with the dose of CNP (Fig. 4f, h, $P<0.05$ ). Therefore, CNP did not affect the expression of FGFR-1/Klotho.

\section{Discussion}

Osteoblasts mediate the process of mineralization by producing ALP and secreting matrix vesicles to facilitate 
hydroxyapatite crystal formation, and this process is regulated by various hormones such as growth hormone, insulin-like growth factor, parathyroid hormone and 1, 25-dihydroxyvitamin D3 [23, 24]. Over the past two decades, increasing evidence has demonstrated CNP importance as a physiological stimulator of longitudinal bone growth, chondrocytic proliferation and hypertrophy, and cartilage matrix synthesis $[9,25]$. Pathologically, our latest study established a rat model of renal osteodystrophy and observed that CNP administration significantly restored calcium phosphate metabolic disorders, hypovitaminosis D, secondary hyperparathyroidism and decreased bone turnover markers, and retarded bone pathological progression [26]. To eliminate disturbance from the neuroendocrine network, the present study cultured osteoblasts with different doses of CNP and found that osteoblastic proliferation could be directly promoted by exogenous CNP in a dose-dependent manner in vitro. However, the proliferative regulation of CNP shows significant diversity among different cell types. Two previous studies from Khambata's and our laboratory revealed that CNP caused a concentrationdependent inhibition of cell proliferation in vascular smooth muscle cells and renal mesangial cells, but led to a concentration-dependent augmentation of cell growth in vascular endothelial cells [8,27]. Although the potential mechanism is still unclear to date, further studies on cell cycle regulation may provide more insight into the different proliferative regulations of CNP on different cells.

Bone turnover biomarkers reflect the metabolic status of the entire skeleton. There are two groups of bone turnover biomarkers: osteoblastic (OC, PICP, tAP and bAP) and osteolytic (ICTP and TRAP) biomarkers [28]. In the present study, both osteoblastic and osteolytic biomarkers were significantly up-regulated in osteoblasts cultured with CNP; more specifically, the larger increase in osteoblastic biomarkers than osteolytic biomarkers may be subject to bone formation. Similarly, Hagiwara et al. [15] cultured osteoblasts with $\mathrm{CNP}\left(10^{-7} \mathrm{M}\right)$ and found that ALP activity became $~ 140 \%$ of the base level accompanied by 2 -fold increase of ALP transcript on the 9th day, and OC transcript was obviously promoted on the 15th day. However, the osteolytic biomarkers were not observed in the above study. Kondo et al. [29] investigated the bone phenotype of a mouse model with elevated plasma CNP concentrations (SAP-CNP-Tg mice) and found that 8-week old SAP-CNP-Tg mice showed enhanced osteoblastic and osteolytic activities, in accordance with elevated serum levels of OC and TRAP. Therefore, CNP is considered as a positive regulator of bone formation both in vitro and in vivo.

Col-X is a short-chain non-fibrillar collagen deposited at sites of new bone formation, and facilitates endochondral ossification by regulating matrix mineralization and compartmentalizing matrix components [30, 31]. Several signaling molecules have been implicated in regulation of Col-X metabolism. These include the positive regulators (thyroid hormones, retinoic acid, bone morphogenetic proteins and transcription factor Runx2), as well as the negative regulator (Indian hedgehog and parathyroid hormone-related protein) [32]. Although CNP is considered as a positive regulator of bone formation, limited evidence exists on the accelerative effect of CNP on Col-X during the process of bone formation. Miyazawa et al. [33] conducted an organ culture study to observed Col-X expression of mouse tibias after CNP $\left(10^{-7} \mathrm{M}\right)$ treatment and found an appreciable increase in the extracellular space positive for Col-X on the 4th day post-culture. In addition, the accelerative effect of CNP on Col-X transcript was also identified in the micromass culture of the chick limb mesenchymal cells and chondrocytes in vitro [34, 35]. Conformably, in the present study, CNP dramatically promoted osteoblastic Col-X expression in both mRNA and protein levels in vitro. However, whether the regulative effect of CNP is a direct consequence on Col-X or mediated by the other cytokines should be further elucidated.

FGF-23 is produced by osteoblasts and acts on the kidneys and parathyroid glands to maintain phosphate homeostasis and regulate vitamin D synthesis in an endocrine manner [36]. Recent studies of human genetic disorders and genetically engineered mice, as well as the in vitro approaches, have proved that FGF-23 overexpression not only suppresses osteoblastic proliferation but also impairs bone mineralization [37, 38]. In a transgenic mouse model overexpressing wild-type human FGF-23, tibial pathology displayed a disorganized and widened growth plate, reduced bone mineral density and impaired mineralization [20]. Teerapornpuntakit et al. [39] cultured rat osteoblast-like UMR-106 cells with FGF-23 $(100 \mathrm{ng} / \mathrm{mL})$, and noted that cell proliferation was significantly down-regulated by FGF- 23 at $48 \mathrm{~h}$. Besides the suppressed osteoblastic proliferation and impaired bone mineralization, FGF-23 can also disturb Col-X metabolism. Wu et al. [40] transfected human FGF-23 into rat mandibular cartilage chondrocytes and observed that the overexpressed FGF-23 significantly inhibited the expression of Col-X transcript in vitro. In our latest study, we established a rat model of renal osteodystrophy and found that serum levels and bone expression of FGF-23 were both significantly elevated in uremic rats; and moreover, serum FGF-23 was negatively correlated with bone Col-X [41]. Currently, many systemic and local factors have been identified to participate in FGF-23 regulation, including calcitriol, phosphate, parathyroid hormone, calcium, and so on $[42,43]$. To the best of our knowledge, the effects of CNP and FGF-23 appear to be opposite during the process of bone formation, 
whereas few studies exist on the interaction between CNP and FGF-23. The present study suggested that CNP treatment inhibited osteoblastic FGF-23 expression in the earlier phase combined with elevated Col-X expression in vitro. Given this background, we hypothesize that CNP may stimulate Col-X expression via the down-regulation of FGF-23. Furthermore, compared with the controls, supernatant OC, tAP and bAP displayed a marked increment in both the low-dose group and high-dose group at $48 \mathrm{~h}$ and $72 \mathrm{~h}$ post-treatment, respectively, whereas the changes in FGF-23 were not significant in both groups at $48 \mathrm{~h}$ and $72 \mathrm{~h}$ treated by CNP. On the other hand, the high-dose group showed a significant increase of Col-X protein compared with in the low-dose group at $72 \mathrm{~h}$ post-treatment, whereas the expression of Col-X at $24 \mathrm{~h}$ and $48 \mathrm{~h}$ was similar in both groups after treated by CNP. Based on these findings, we speculate that this may be due to a shorter half-life of CNP and the hysteresis effects of FGF-23.

FGF-23-FGFR-1 complex plays regulative roles in bone development and disease [44]. Wang et al. [21] transfected human FGF-23 into osteoblasts in vitro and found that overexpressed FGF-23 obviously suppressed nodule formation and mineralization accompanied by enhanced phosphorylation of FGFR-1. On the contrary, in a mouse model of X-linked hypophosphatemia, Xiao et al. [45] found that the conditional deletion of Fgfr-1 in osteocytes contributed to a $30 \%$ reduction in bone FGF- 23 expression and a $70 \%$ reduction in serum FGF-23 concentration as well as a significant improvement in rickets and osteomalacia. On the other hand, binding of FGF-23 to the canonical FGFR-1 requires the obligatory co-receptor Klotho [46]. Shalhoub et al. [38] cultured osteoblasts with FGF-23 in the absence or presence of soluble Klotho, and noted that FGF-23 plus Klotho led to inhibition of mineralization and osteoblast activity markers on day 14; in contrast, neither FGF-23 nor Klotho exposure alone affected proliferation of day 4 growth phase cells or mineralization of day 14 cultures. However, the effects of CNP on FGFR-1/Klotho are seldom reported in osteoblasts to data. In the present study, FGF-23 mRNA and protein were significantly down-regulated by CNP in osteoblasts, but the expression of FGFR-1/Klotho had no significant change. Thus, FGF-23 may elicit its effects in a FGFR-1/Klotho-independent fashion in osteoblast.

FGF-23/ mitogen-activated protein kinase (MAPK) signaling pathway is known to be suppressing osteoblastic activity and this is via MAPK activation [38]. However, the crosstalk between CNP and FGF-23/ MAPK signaling has not been extensively studied so far. Yasoda et al. [47] treated tibial explants with CNP $\left(10^{-6}\right.$ and $\left.10^{-7} \mathrm{M}\right)$ or its second messenger, cGMP $\left(10^{-5} \mathrm{M}\right)$, before addition of FGF-2 ( $2 \mathrm{ng} / \mathrm{ml}$, similar to FGF-23) and found that FGF-2-induced phosphorylation of extracellular regulated protein kinase (ERK) $1 / 2$ was markedly decreased in a dose-dependent fashion. Moreover, identical results were obtained using the chondrogenic cell line ATDC5. In our previous study, we established a renal osteodystrophy rat model to identify whether $\mathrm{CNP}$ could attenuate renal osteodystrophy through the inhibition of FGF-23 cascades, and found that a continuous infusion of CNP $(0.05 \mu \mathrm{g} / \mathrm{kg} / \mathrm{min} \times 1 \mathrm{~h})$ significantly inhibited the expression of FGF-23, RAF-1/phosphoRAF-1, and downstream ERK/phospho-ERK in bone tissue [26]. As for FGF-23 signaling, no dose effect of CNP was observed in the present study. The expression of FGF-23 were significantly suppressed in both low-dose $(10 \mathrm{pmol} / \mathrm{L})$ and high-dose $(100 \mathrm{pmol} / \mathrm{L})$ groups at $24 \mathrm{~h}$ post-treatment. Based on the transcription and protein levels of FGF-23, there was a trend toward low-dose group to experience a more obvious decrease. A further research should be undertaken to observe the potential mechanism.

\section{Conclusions}

In summary, our study revealed, for the first time, that exogenous CNP stimulated osteoblastic proliferation and Col-X expression via the down-regulation of FGF-23 possibly in vitro. However, FGFR-1 and Klotho were not influenced by CNP in osteoblasts. According to the findings of present study, the specific mechanism of the interaction between CNP and FGF-23 in osteoblasts is still unclear. Currently, the further study on osteoblasts cultured with CNP and FGF-23 inhibitor is being taken in our laboratory.

\section{Abbreviations}

ALP: Alkaline phosphatase; bAP: Bone-specific alkaline phosphatase; cGMP: Cyclic guanosine monophosphate; CNP: C-type natriuretic peptide Col-X: Collagen X; ICTP: Cross-linked carboxyterminal telopeptide of type I collagen; ELISA: Enzyme-linked immunosorbent assay; ERK: Extracellular regulated protein kinase; FGF-23: Fibroblast growth factor-23; FGFR1: Fibroblast growth factor receptor-1; GAPDH: Glyceraldehyde-3-phosphate dehydrogenase; MAPK: Mitogen-activated protein kinase; NPR-B: Natriuretic peptide receptor-B; OD: Optical density; OC: Osteocalcin; PBS: Phosphate buffer saline; PICP: Procollagen type I carboxy-terminal propeptide; tAP: Total alkaline phosphatase; TBST: Tris-buffered saline tween; TRAP: Tartrate-resistant acid phosphatase; IOD/area: The cumulative optical density per unit area; MTT assay: 3-[4,5-dimethylthiazolyl]-2,5-diphenyltetrazolium bromide assay

\section{Acknowledgements}

Not applicable.

\section{Authors' contributions}

Peng Hu conceptualized and designed the study, coordinated and supervised data collection, and critically reviewed the manuscript for important intellectual content. Wei Xia Chen and Hui Hui Liu conducted the experiments and drafted the manuscript. Rui Xue Li, Goshgar Mammadov, Jing Jing Wang, Fei Fei Liu, Sama Samadli, Yang Fang Wu, Dong Dong Zhang and Huang Huang Luo collected data and carried out the initial analyses. All authors approved the final manuscript as submitted and agree to be accountable for all aspects of the work. 


\section{Funding}

This study was supported by the National Natural Science Foundation of China (No. 81570637).

\section{Availability of data and materials}

The datasets generated and/or analyzed during current study are available from the corresponding author on reasonable request.

\section{Ethics approval and consent to participate}

The study was approved by the Research Ethics Commission of the First Affiliated Hospital of Anhui Medical University (No. LLSC20150009).

\section{Consent for publication}

No applicable.

\section{Competing interests}

The authors have no conflicts of interest relevant to this article to disclose.

Received: 17 December 2019 Accepted: 3 June 2020

Published online: 09 June 2020

\section{References}

1. Yeung VT, Ho SK, Nicholls MG, Cockram CS. Binding of CNP-22 and CNP-53 to cultured mouse astrocytes and effects on cyclic GMP. Peptides. 1996; 17(1):101-6

2. Hunt PJ, Richards AM, Espiner EA, Nicholls MG, Yandle TG. Bioactivity and metabolism of C-type natriuretic peptide in normal man. J Clin Endocrinol Metab. 1994;78(6):1428-35.

3. Espiner E, Prickett T, Olney R. Plasma C-type natriuretic peptide: emerging applications in disorders of skeletal growth. Horm Res Paediatr. 2018:90(6): 345-57.

4. Matsuo A, Nagai-Okatani C, Nishigori M, Kangawa K, Minamino N. Natriuretic peptides in human heart: novel insight into their molecular forms, functions, and diagnostic use. Peptides. 2019;111:3-17.

5. Hu P, Lu L, Hu B, Qin YH. Renal action of C-type natriuretic peptide: advocating the isolated perfused rat kidney model. Saudi I Kidney Dis Transpl. 2010:21:613-20.

6. Bubb KJ, Aubdool AA, Moyes AJ, Lewis S, Drayton JP, Tang O, et al. Endothelial C-type natriuretic peptide is a critical regulator of angiogenesis and vascular remodeling. Circulation. 2019;139:1612-28.

7. Hu P, Zhang XC, Kong HB, Xia X, Hu B, Qin YH. Exogenous C-type natriuretic peptide infusion ameliorates unilateral ureteral obstruction-induced tubulointerstitial fibrosis in rats. Lab Invest. 2015;95:263-72.

8. Wu YF, Zhang DD, Liu SY, Luo HH, Jiang GM, Xu Y, et al. C-type natriuretic peptide dampens fibroblast growth factor-23 expression through MAPK signaling pathway in human mesangial cells. J Interferon Cytokine Res. 2018;38:500-9.

9. Tassano E, Buttgereit J, Bader M, Lerone M, Divizia MT, Bocciardi R, et al. Genotype-phenotype correlation of 2q37 deletions including NPPC gene associated with skeletal malformations. PLoS One. 2013;8:e66048.

10. Hisado-Oliva A, Ruzafa-Martin A, Sentchordi L, Funari MFA, Bezanilla-López C, Alonso-Bernáldez M, et al. Mutations in C-natriuretic peptide (NPPC): a novel cause of autosomal dominant short stature. Genet Med. 2018;20:91-7.

11. Olney RC, Bükülmez $H$, Bartels $C F$, Prickett $T C$, Espiner EA, Potter $L R$, et al. Heterozygous mutations in natriuretic peptide receptor-B (NPR2) are associated with short stature. J Clin Endocrinol Metab. 2006;91:1229-32.

12. Wang SR, Jacobsen CM, Carmichael H, Edmund AB, Robinson JW, Olney RC, et al. Heterozygous mutations in natriuretic peptide receptor-B (NPR2) gene as a cause of short stature. Hum Mutat. 2015:36:474-81.

13. Chusho H, Tamura N, Ogawa Y, Yasoda A, Suda M, Miyazawa T, et al. Dwarfism and early death in mice lacking C-type natriuretic peptide. Proc Natl Acad Sci U S A. 2001;98:4016-21.

14. Tamura N, Doolittle LK, Hammer RE, Shelton JM, Richardson JA, Garbers DL. Critical roles of the guanylyl cyclase B receptor in endochondral ossification and development of female reproductive organs. Proc Natl Acad Sci U S A. 2004:101:17300-5

15. Hagiwara H, Inoue A, Yamaguchi A, Yokose S, Furuya M, Tanaka S, et al. cGMP produced in response to ANP and CNP regulates proliferation and differentiation of osteoblastic cells. Am J Physiol. 1996;270:C1311-8.

16. Suda M, Tanaka K, Fukushima M, Natsui K, Yasoda A, Komatsu Y, et al. Ctype natriuretic peptide as an autocrine/paracrine regulator of osteoblast.
Evidence for possible presence of bone natriuretic peptide system. Biochem Biophys Res Commun. 1996:223:1-6.

17. Hu P, Huang BY, Xia X, Xuan Q, Hu B, Qin YH. Therapeutic effect of CNP on renal osteodystrophy by antagonizing the FGF-23/MAPK pathway. J Recept Signal Transduct Res. 2016;36:213-9.

18. Takei Y, Minamizaki T, Yoshiko Y. Functional diversity of fibroblast growth factors in bone formation. Int J Endocrinol. 2015;2015:729352.

19. Shimada T, Kakitani M, Yamazaki Y, Hasegawa H, Takeuchi Y, Fujita T, et al. Targeted ablation of Fgf23 demonstrates an essential physiological role of FGF23 in phosphate and vitamin D metabolism. J Clin Invest. 2004;113:5618.

20. Larsson T, Marsell R, Schipani E, Ohlsson C, Ljunggren O, Tenenhouse HS, et al. Transgenic mice expressing fibroblast growth factor 23 under the control of the alpha1(I) collagen promoter exhibit growth retardation, osteomalacia, and disturbed phosphate homeostasis. Endocrinology. 2004; 145:3087-94.

21. Wang H, Yoshiko Y, Yamamoto R, Minamizaki T, Kozai K, Tanne K, et al. Overexpression of fibroblast growth factor 23 suppresses osteoblast differentiation and matrix mineralization in vitro. J Bone Miner Res. 2008;23: 939-48.

22. Declercq $H$, Van den Vreken N, De Maeyer E, Verbeeck R, Schacht E, De Ridder $\mathrm{L}$, et al. Isolation, proliferation and differentiation of osteoblastic cells to study cell/biomaterial interactions: comparison of different isolation techniques and source. Biomaterials. 2004;25:757-68.

23. Florencio-Silva R, Sasso GR, Sasso-Cerri E, Simões MJ, Cerri PS. Biology of bone tissue: structure, function, and factors that influence bone cells. Biomed Res Int. 2015;2015:421746.

24. Kartsogiannis V, Ng KW. Cell lines and primary cell cultures in the study of bone cell biology. Mol Cell Endocrinol. 2004;228:79-102.

25. Yasoda A, Nakao K. Translational research of the activation of the C-type natriuretic peptide (CNP)-guanylyl cyclase-B pathway for skeletal dysplasia. In: Nakao K, Minato N, Uemoto S, editors. In: innovative medicine: basic research and development. Tokyo: Springer; 2015.

26. Zhang DD, Wu YF, Chen WX, Xu Y, Liu SY, Luo HH, et al. C-type natriuretic peptide attenuates renal osteodystrophy through inhibition of FGF-23/ MAPK signaling. Exp Mol Med. 2019:51:70.

27. Khambata RS, Panayiotou CM, Hobbs AJ. Natriuretic peptide receptor-3 underpins the disparate regulation of endothelial and vascular smooth muscle cell proliferation by $\mathrm{C}$-type natriuretic peptide. Version $2 . \mathrm{Br} \mathrm{J}$ Pharmacol. 2011;164:584-97.

28. Szulc P. Bone turnover: biology and assessment tools. Best Pract Res Clin Endocrinol Metab. 2018:32:725-38.

29. Kondo E, Yasoda A, Fujii T, Nakao K, Yamashita Y, Ueda-Sakane Y, et al. Increased bone turnover and possible accelerated fracture healing in a murine model with an increased circulating C-type natriuretic peptide. Endocrinology. 2015;156:2518-29.

30. Luckman SP, Rees E, Kwan AP. Partial characterization of cell-type X collagen interactions. Biochem J. 2003;372:485-93.

31. Shen $\mathrm{G}$. The role of type $X$ collagen in facilitating and regulating endochondral ossification of articular cartilage. Orthod Craniofac Res. 2005;8:11-7.

32. Adams SL, Cohen AJ, Lassová L. Integration of signaling pathways regulating chondrocyte differentiation during endochondral bone formation. J Cell Physiol, 2007:213:635-41.

33. Miyazawa T, Ogawa Y, Chusho H, Yasoda A, Tamura N, Komatsu Y, et al. Cyclic GMP-dependent protein kinase II plays a critical role in C-type natriuretic peptide-mediated endochondral ossification. Endocrinology. 2002;143:3604-10

34. Alan T, Tufan AC. C-type natriuretic peptide regulation of limb mesenchymal chondrogenesis is accompanied by altered $\mathrm{N}$-cadherin and collagen type X-related functions. J Cell Biochem. 2008;105:227-35.

35. Nakao K, Okubo Y, Yasoda A, Koyama N, Osawa K, Isobe Y, et al. The effects of C-type natriuretic peptide on craniofacial skeletogenesis. J Dent Res. 2013;92:58-64.

36. Gonciulea AR, Jan De Beur SM. Fibroblast growth factor 23-mediated bone disease. Endocrinol Metab Clin North Am. 2017;46:19-39.

37. ADHR Consortium. Autosomal dominant hypophosphataemic rickets is associated with mutations in FGF23. Nat Genet. 2000;26:345-8.

38. Shalhoub V, Ward SC, Sun B, Stevens J, Renshaw L, Hawkins N, et al. Fibroblast growth factor 23 (FGF23) and alpha-klotho stimulate osteoblastic MC3T3.E1 cell proliferation and inhibit mineralization. Calcif Tissue Int. 2011; 89:140-50. 
39. Teerapornpuntakit J, Wongdee K, Krishnamra N, Charoenphandhu N. Expression of osteoclastogenic factor transcripts in osteoblast-like UMR-106 cells after exposure to FGF-23 or FGF-23 combined with parathyroid hormone. Cell Biol Int. 2016:40:329-40.

40. Wu Y, Zhang J, Chen F. The effects of elevated fibroblast growth factor 23 on mandibular growth in rats. Arch Oral Biol. 2018;95:156-64.

41. Liu SY, Zhang DD, Wu YF, Luo HH, Jiang GM, Xu Y, et al. Fibroblast growth factor-23 may serve as a novel biomarker for renal osteodystrophy progression. Int J Mol Med. 2019;43:535-46.

42. Rhee Y, Bivi N, Farrow E, Lezcano V, Plotkin LI, White KE, et al. Parathyroid hormone receptor signaling in osteocytes increases the expression of fibroblast growth factor-23 in vitro and in vivo. Bone. 2011;49:636-43.

43. Perwad F, Azam N, Zhang MY, Yamashita T, Tenenhouse HS, Portale AA. Dietary and serum phosphorus regulate fibroblast growth factor 23 expression and 1,25-dihydroxyvitamin D metabolism in mice. Endocrinology. 2005;146:5358-64.

44. Su N, Jin M, Chen L. Role of FGF/FGFR signaling in skeletal development and homeostasis: learning from mouse models. Bone Res. 2014;2:14003.

45. Xiao Z, Huang J, Cao L, Liang Y, Han X, Quarles LD. Osteocyte-specific deletion of Fgfr1 suppresses FGF23. PLoS One. 2014;9:e104154.

46. Urakawa I, Yamazaki Y, Shimada T, lijima K, Hasegawa H, Okawa K, et al. Klotho converts canonical FGF receptor into a specific receptor for FGF23. Nature. 2006;444:770-4.

47. Yasoda A, Komatsu Y, Chusho H, Miyazawa T, Ozasa A, Miura M, et al. Overexpression of CNP in chondrocytes rescues achondroplasia through a MAPK-dependent pathway. Nat Med. 2004;10(1):80-6.

\section{Publisher's Note}

Springer Nature remains neutral with regard to jurisdictional claims in published maps and institutional affiliations.

Ready to submit your research? Choose BMC and benefit from:

- fast, convenient online submission

- thorough peer review by experienced researchers in your field

- rapid publication on acceptance

- support for research data, including large and complex data types

- gold Open Access which fosters wider collaboration and increased citations

- maximum visibility for your research: over $100 \mathrm{M}$ website views per year

At $\mathrm{BMC}$, research is always in progress.

Learn more biomedcentral.com/submissions 